\title{
AOR
}

Selected Papers of \#AolR2020: The $21^{\text {st }}$ Annual Conference of the Association of Internet Researchers Virtual Event / 27-31 October 2020

\section{RESEARCHING ONLINE LABOR STRIKE AND PROTEST PREDICTION TECHNOLOGIES}

Gabriel Grill

University of Michigan

\section{Introduction}

Social media platforms have been lauded for enabling and organizing social movements both online and offline. Yet in contrast to these hopeful imaginaries are authoritative efforts to surveil and control social media activity at scale and in near-real time using advanced techniques from data science (Tufekci, 2017). This has manifested for instance in recent government-funded research to predict US protests following the election of President Trump in 2016 (Renaud et al., 2018). This work is part of an emerging computer science research field focused on online "civil unrest prediction" dedicated to forecasting protests across the globe (e.g. Indonesia, Brazil, UK, Venezuela and Australia). Researchers often draw upon established data science techniques such as event detection and prediction, but also approaches specifically tailored towards surveilling social movements are conceived. Besides furthering the academic knowledge-base on civil unrest and protests, the works in this field envision to support a variety of stakeholders with different interests: Governments, the military and law enforcement driven by securitization, techno-optimistic promises of efficiency and possibilities for pro-active/preemptive security interventions (Hälterlein \& Ostermeier, 2018; Vogel et al., 2016); Industries driven by economic interests to anticipate labor organizing and other disruptions, e.g. to avoid delays across supply chains or to develop new insurance products; Human rights organizations interested in making offline protests across the globe more visible to broader publics and/or to detect/predict human rights abuses connected to them while understaffed.

The variety of, also conflicting, interests vested in this research, data and technology across different sectors highlights complex tensions and a malleability of the technology. This paper is part of ongoing work concerned with mapping the recent history of civil unrest prediction on social media platforms as well as an analysis of associated technologies, discourses and power relations. This analysis is based on Suggested Citation (APA): Grill, G. (2020, October). Researching online labor strike and protest prediction technology. Paper presented at AolR 2020: The 21 ${ }^{\text {th }}$ Annual Conference of the Association of Internet Researchers. Virtual Event: AolR. Retrieved from http://spir.aoir.org. 
documents (Bowen, 2009) composed of scholarly literature and other public online artifacts or materials discussing/detailing applications for companies, governments or other actors. Since in this area few details are known about technologies and their uses, e.g. due to company and government secrets, I hope this work can give interesting new perspectives through analyzing publicly available research papers, which in some cases have also been a basis for the founding of spin-off companies. I think this work is potentially valuable to activists and could contribute to a needed public debate on the role of protest surveillance in democratic societies.

My research approach is grounded in Situational Analysis (Clarke et al., 2017) as I study networks of positions, discourses, technologies, institutions and other actors which situate, construct and stabilize civil unrest prediction practices. The approach further involves coding, theme extraction, mapping and Critical Discourse Analysis (Hoffmann et al., 2018; Mullet, 2018).

\section{Discussion}

These recent trends in protest social media surveillance are not new and can be considered a continuation of long-standing risk assessment efforts to anticipate disruption and unrest. Several research efforts and products that target protests in countries with emerging and developing economies can also be understood as building upon long histories of scientific experimentation and surveillance on marginal populations and colonialism (Murphy, 2017). The technological approaches of research I investigated varied in terms of machine learning methods, types of targeted events, accuracy and forecasting timeframes (from several hours to days, and in some cases weeks). In alignment with the underlying big data ideology, some prediction systems employed a great variety of different data sources. Early examples of online protest prediction research were based on blog posts to study e.g. "Muslim reaction" (Colbaugh \& Glass, 2010, p. 40) and predict "successful mobilization and protest events [..] that became large and self-sustaining". Contemporary research on online social data was focused more on platforms, such as Twitter, Facebook and Tumbler.

Social media users were framed by some researchers as mechanistic public data generators from which valuable information could be extracted for certain means, e.g. referring to the practice as reading "public and accessible [..] open source data" (Agarwal, 2017, p. 2) from "human-sensors" (p. 2) to acquire information on the offline world. This view both dehumanizes users and activists framed as sensors and aims to justify research on the basis of data being publicly available, which is problematic stance (Boyd \& Crawford, 2012). Perspectives of protestors were often not considered or discussed by researchers, instead protests were often framed as risks to be controlled or anticipated. Most researchers and companies framed protests or labor strikes as sources of disruptions to be diverted for security and economic reasons, which is certainly a controversial and problematic position because of the central and protected role of protests in democracies. One company for instance referred to their system as a "shitstorm insurance" (DIA Insurtechs, 2018), thereby concerningly framing those who voice grievances as a "shitstorm". If protests lose power for disrupting daily life and generating attention, then their purpose may be defeated or at last challenged. In turn the goal of generally reducing "disruptiveness" shared by some in this line of 
research and product development, can be considered as authoritative and problematic in the context of democratic participation. Furthermore, technologies anticipating the forming of social movements and/or detecting planning activates online, may matter significantly to information campaigns aimed at "drowning critical posts in a sea of other topics" (Tufekci, 2017, p. 237) to undermine reach and organizing. Still, prediction in this context is a highly ambiguous task which in turn also creates possibilities to evade this algorithmic gaze.

\section{References}

Agarwal, S. (2017). Open source social media intelligence for enabling government applications: Extended abstract. ACM SIGWEB Newsletter, Summer, 1-19. https://doi.org/10.1145/3110394.3110397

Bowen, G. A. (2009). Document Analysis as a Qualitative Research Method. Qualitative Research Journal, 9(2), 27-40. https://doi.org/10.3316/QRJ0902027

Boyd, D., \& Crawford, K. (2012). Critical questions for big data: Provocations for a cultural, technological, and scholarly phenomenon. Information, Communication \& Society, 15(5), 662-679.

Clarke, A. E., Friese, C., \& Washburn, R. S. (2017). Situational analysis: Grounded theory after the interpretive turn. Sage Publications.

Colbaugh, R., \& Glass, K. (2010). Early warning analysis for social diffusion events. 2010 IEEE International Conference on Intelligence and Security Informatics, 3742. https://doi.org/10.1109/ISI.2010.5484778

DIA Insurtechs. (2018). DIA TV | Digital Insurance Agenda. http://www.digitalinsuranceagenda.com/pagina-dia-tv.php?keyword=Prewave

Hälterlein, J., \& Ostermeier, L. (2018). Special Issue: Predictive Security Technologies. European Journal for Security Research, 3(2), 91-94. https://doi.org/10.1007/s41125-018-0034-z

Hoffmann, A. L., Proferes, N., \& Zimmer, M. (2018). "Making the world more open and connected": Mark Zuckerberg and the discursive construction of Facebook and its users. New Media \& Society, 20(1), 199-218. https://doi.org/10.1177/1461444816660784

Mullet, D. R. (2018). A General Critical Discourse Analysis Framework for Educational Research. Journal of Advanced Academics, 29(2), 116-142. https://doi.org/10.1177/1932202X18758260

Murphy, M. (2017). The Economization of Life. Duke University Press. http://read.dukeupress.edu/lookup/doi/10.1215/9780822373216

Renaud, M., Korolov, R., Mendonça, D., \& Wallace, W. (2018). Social Network Structure as a Predictor of Social Behavior: The Case of Protest in the 2016 US Presidential Election. XVIII International Conference on Data Science and Intelligent Analysis of Information, 267-278.

Tufekci, Z. (2017). Twitter and tear gas: The power and fragility of networked protest. Yale University Press.

Vogel, K., Balmer, B. L., Weiss Evans, S., Kroener, I., Matsumoto, M., \& Rappert, B. (2016). Knowledge and security. MIT Press. 